\title{
Chitosan-zinc chelate improves intestinal structure and mucosal function and decreases apoptosis in ileal mucosal epithelial cells in weaned pigs
}

\author{
Xin-Yan Han, Yuan-Fei Ma, Meng-Yuan Lv, Zhi-Peng Wu and Li-Chun Qian* \\ Key Laboratory of Animal Nutrition and Feed Science in East China, Ministry of Agriculture, College of Animal Science, \\ Zhejiang University, 866 Yuhangtang Road, Hangzhou 310058, People's Republic of China
}

(Submitted 14 May 2013 - Final revision received 15 November 2013 - Accepted 18 November 2013 - First published online 6 January 2014)

\section{Abstract}

The present study was conducted to investigate the effects of chitosan (CS)-Zn on intestinal morphology, mucosal epithelial cell apoptosis and mucosal immune function in weanling pigs. A total of 150 weanling barrows with a body weight of $7 \cdot 2 \mathrm{~kg}$ were randomly allocated into five groups. A basal diet without $\mathrm{Zn}$ supplementation was used as the control and other four groups were fed the control diet supplemented with 50 or $100 \mathrm{mg} / \mathrm{kg}$ of $\mathrm{Zn}$ as CS-Zn, $100 \mathrm{mg} / \mathrm{kg}$ of $\mathrm{Zn}$ as $\mathrm{ZnSO}_{4}$ and $3000 \mathrm{mg} / \mathrm{kg}$ of $\mathrm{Zn}$ as ZnO, respectively. The feeding trial lasted for $28 \mathrm{~d}$. The results showed that serum diamine oxidase activities, D-lactate levels and endotoxin contents were lower in pigs fed dietary $100 \mathrm{mg} / \mathrm{kg}$ of $\mathrm{Zn}$ as CS-Zn or $3000 \mathrm{mg} / \mathrm{kg}$ of $\mathrm{Zn}$ as $\mathrm{ZnO}$ than in pigs fed the control or $100 \mathrm{mg} \mathrm{Zn/kg}$ as $\mathrm{ZnSO} 4$ diet. The ratios of the villus height:crypt depth of the duodenum, jejunum and ileum were higher in pigs that received $100 \mathrm{mg} / \mathrm{kg}$ of $\mathrm{Zn}$ as CS-Zn or a high level of $\mathrm{Zn}$ as $\mathrm{ZnO}$ than in pigs fed the control diet. Moreover, terminal deoxynucleotidyl transferase-mediated deoxyuridine triphosphate-biotin nick end labelling (TUNEL)-stained ileal epithelial cells were found in the control group, and apoptotic cells did not appear prominently in pigs that received the $100 \mathrm{mg} / \mathrm{kg}$ of CS-Zn or ZnO diet. Secretory IgA concentration in ileal mucus was increased in the dietary group that received $100 \mathrm{mg} / \mathrm{kg}$ of CS-Zn or ZnO. These results indicated that dietary $100 \mathrm{mg}$ CS-Zn/kg had similar biological effects to dietary $3000 \mathrm{mg} \mathrm{ZnO} / \mathrm{kg}$ on intestinal morphology, mucosal epithelial cell apoptosis and mucosal immune function.

\section{Key words: Apoptosis: Intestinal morphology: Chitosan-zinc: Weaned pigs}

$\mathrm{Zn}$ is found in small amounts within the animal body. A pig weighing $100 \mathrm{~kg}$ contains less than $2000 \mathrm{mg} \mathrm{Zn}^{(1)}$; however, $\mathrm{Zn}$ plays important roles in several metabolic functions. Most enzymes in animals require $\mathrm{Zn}$ to maintain their normal structure and function, and thousands of transcription factors contain one or more $\mathrm{Zn}$ atoms. $\mathrm{Zn}$ is a cofactor of more than 300 metalloenzymes, and it is required for at least one enzyme in all six enzyme classes ${ }^{(2)}$. Therefore, sufficient amount of $\mathrm{Zn}$ is essential for animal growth and development. Usually, the amount of $\mathrm{Zn}$ supplied to pig diets largely exceeds the physiological requirements. Several studies ${ }^{(3-7)}$ have indicated that pharmacological levels of dietary $\mathrm{ZnO}$ (1000-5000 mg/kg) could improve growth performance and reduce the prevalence of diarrhoea in weaning piglets. However, the subsequent application of too much $\mathrm{Zn}$ on soil may be toxic to plants and micro-organisms. Extensive feeding of high dietary $\mathrm{Zn}$ has led to an environmental concern due to the high amount of $\mathrm{Zn}$ excreted in the faeces ${ }^{(8,9)}$. Thus, there is a need to find an effective and environmentally safe alternative.

Previously, it has been shown that bioavailability of organic $\mathrm{Zn}$ was higher than that of inorganic $\mathrm{Zn}$ in pigs $^{(9-11)}$. Similarly, it has been reported that the bioavailability of $\mathrm{Zn}$-lysine or $\mathrm{Zn}$-methionine was higher than that of $\mathrm{ZnO}^{(12)}$. $\mathrm{Zn}$ is necessary in maintaining intestinal wall integrity, and it has beneficial effects on enteropathogenic Escherichia coli infection ${ }^{(13)}$. The positive effects of $\mathrm{Zn}$ supplementation also include increasing the Th1 immune response and affecting intestinal bacterial populations $^{(14)}$. Studies have shown that the microbiota in the gastrointestinal tract could reduce the quantity of $\mathrm{Zn}$, as there is a competition for $\mathrm{Zn}$ utilisation by the microbiota and host gastrointestinal tract ${ }^{(15)}$. High levels of $\mathrm{Zn}$ as $\mathrm{ZnO}$ in diets of weanling pigs could increase intestinal tight junction protein expression and decrease intestinal permeability ${ }^{(16)}$.

Chitosan (CS) $\mathrm{Zn}$ is a chelate of $\mathrm{Zn}^{2+}$ with CS, and previous studies on the chelation of $\mathrm{Zn}^{2+}$ with CS were focused on its applications to the separation of metal ions or the treatment of waste water ${ }^{(17)}$. When CS binds to $\mathrm{Zn}^{2+}$ through $\mathrm{N}$, O or a combination of both, the binding might enhance the biological activity of the chelate ${ }^{(18)}$. Few studies have been reported on the application of $\mathrm{CS}-$ metal complexes in animal production. Our previous study has shown that CS-Zn could enhance growth performance and decrease the prevalence

Abbreviations: CS, chitosan; DAO, diamine oxidase; sIgA, secretory IgA; TUNEL, terminal deoxynucleotidyl transferase-mediated deoxyuridine triphosphate-biotin nick end labelling.

*Corresponding author: L.-C. Qian, fax +86 57188982650 , email lcqian@zju.edu.cn 
of diarrhoea in weaned piglets. The efficiency of CS-Zn at a level of $100 \mathrm{mg} \mathrm{Zn} / \mathrm{kg}$ has been found to be as effective as $3000 \mathrm{mg} \mathrm{Zn} / \mathrm{kg}$ as $\mathrm{ZnO}^{(19)}$, which would be beneficial for the environment and for sustaining swine production. Therefore, the objective of the present study was to investigate the impact of dietary CS-Zn on intestinal morphology, mucosal epithelial cell apoptosis and mucosal immune function in weanling pigs.

\section{Materials and methods}

\section{Animals, housing and feeding}

The present study followed the institutional and national guidelines for the care and use of animals. All experimental procedures involving animal care and sampling were approved by the Ethics Committee for Animal Experimentation of Zhejiang University. A total of 150 weanling barrows (25 (SEM 2) d of age, Landrace $\times$ Yorkshire $\times$ Duroc) weighing $7 \cdot 2$ (sEm $0 \cdot 3) \mathrm{kg}$ were randomly allocated to five treatments. Each treatment was replicated three times, with ten pigs per replicate (i.e. pen). The group fed a basal diet without $\mathrm{Zn}$ supplementation was used as the control. The other four groups were fed the control diet supplemented with 50 or $100 \mathrm{mg}$ $\mathrm{Zn} / \mathrm{kg}$ as CS-Zn, $100 \mathrm{mg} \mathrm{Zn/kg} \mathrm{as} \mathrm{ZnSO}_{4}, 3000 \mathrm{mg} \mathrm{Zn/kg} \mathrm{as}$ $\mathrm{ZnO}$, respectively. CS-Zn, a Zn-CS chelate compound containing $16 \cdot 1 \%$ of $\mathrm{Zn}$, was provided by Feed Science Institute of Zhejiang University. The basal diet contained $28.30 \mathrm{mg} / \mathrm{kg}$ of $\mathrm{Zn}$, and all nutrients met or exceeded the National Research Council $^{(20)}$ recommendations for weanling piglets. The basal diet for pigs contained $62 \%$ maize, $17 \cdot 5 \%$ soyabean meal, $3 \%$ extruded soyabean, 5\% fishmeal, 5\% whey powder, $1 \%$ wheat bran, $0.5 \%$ soyabean oil, $2 \%$ glucose and $4 \% \mathrm{mineral} /$ vitamin premix. The nutrient levels of the diet were as follows: $13.7 \mathrm{MJ} / \mathrm{kg}$ calculated digestible energy, $18 \%$ crude protein, $1.5 \mathrm{~g}$ Lys $/ \mathrm{kg}, 0.9 \mathrm{~g} \mathrm{Met}+\mathrm{Cys} / \mathrm{kg}$. All pigs were housed in a curtain-sided pig barn with $3.0 \times 4.0 \mathrm{~m}$ pens. The pens had concrete floors, and each pen was equipped with a feeder and nipple drinker. The pigs were given ad libitum access to feed and water. The feeding trial lasted $28 \mathrm{~d}$ after a $7 \mathrm{~d}$ adaptation period.

\section{Sample collection}

At the end of the feeding trial, thirty pigs (without feed for $12 \mathrm{~h}$, two piglets per pen and six piglets per treatment) were randomly selected and then killed with sodium pentobarbital ( $50 \mathrm{mg} / \mathrm{kg}$ body weight) to collect intestinal samples. Blood samples were collected from the anterior vena cava of pigs, and centrifuged at $4^{\circ} \mathrm{C}$ for $15 \mathrm{~min}$ at $3000 \mathrm{~g}$, and serum was obtained. Serum was transferred to Eppendorf tubes, respectively, snap-frozen in liquid $\mathrm{N}_{2}$ and stored at $-70^{\circ} \mathrm{C}$ until chemical analysis. Ileal tissue was removed, dissected and washed carefully with normal saline. Ileal mucus was collected with a smooth glass rod and transferred to an Eppendorf tube. The samples were snap-frozen in liquid $\mathrm{N}_{2}$ and stored at $-70^{\circ} \mathrm{C}$.

\section{Sample preparation}

The duodenal (about $5 \mathrm{~cm}$ from the pyloric-duodenal junction), mid-jejunal and ileal (about $10 \mathrm{~cm}$ from the ilealcaecal junction) segments were sampled and fixed in buffered formalin $(10 \%)$ at $4^{\circ} \mathrm{C}$ for morphometric analysis. Each sample was embedded with paraffin wax and sectioned at $5 \mu \mathrm{m}$ on a rotary microtome. Then, the sections were stained with haematoxylin and eosin. Villus height and crypt depth were measured according to the technique of Goodlad et al. ${ }^{(21)}$. Well-oriented crypt-villus units were selected for each intestinal cross-section, and the average of fifteen measurements was recorded. The sections were stained with haematoxylin and eosin. Evaluations were made under a light microscope using a 1/100 ocular scale (Olympus). Morphological indices were determined using an image processing and analysis system (version 1; Leica Imaging Systems Limited).

\section{Tissue processing and immunohistochemistry}

Formalin-fixed, paraffin wax-embedded ileal samples from treatments were sectioned at $5-7 \mu \mathrm{m}$ on a rotary microtome and analysed for apoptosis in mucosal epithelial cells with a modified terminal deoxynucleotidyl transferase-mediated deoxyuridine triphosphate-biotin nick end labelling (TUNEL) method $^{(22)}$. In brief, sections were deparaffinised in xylene and rehydrated with distilled water, and rinsed in PBS ( $0.1 \mathrm{~mol} / \mathrm{l}$, $\mathrm{pH} 7 \cdot 2$ ). Endogenous peroxidase expression was inactivated by incubation of tissue sections with $0.3 \% \mathrm{H}_{2} \mathrm{O}_{2}$ in methanol for $30 \mathrm{~min}$ at room temperature. After treatment with proteinase $\mathrm{K}$, the sections were incubated with $3^{\prime}$-terminal transferase in the presence of biotin-labelled deoxyuridine triphosphate (dUTP) in a moist chamber at $37^{\circ} \mathrm{C}$ for $1 \mathrm{~h}$. Then, the sections were incubated with sheep anti-fluorescein antibody conjugated with horseradish peroxidase at $37^{\circ} \mathrm{C}$ for $30 \mathrm{~min}$, washed with PBS $(3 \times, 5 \mathrm{~min})$ and treated with $3,3^{\prime}$-diaminobenzidine $/ \mathrm{H}_{2} \mathrm{O}_{2}$ (0.5 $\mathrm{mg} / \mathrm{ml}, 3,3^{\prime}$-diaminobenzidine with $0.003 \% \quad \mathrm{H}_{2} \mathrm{O}_{2}$ in $0.05 \mathrm{~m}$-Tris buffer, $\mathrm{pH} \mathrm{7.6)}$ at room temperature for $10 \mathrm{~min}$. They were determined either without staining or after faint counterstaining with haematoxylin.

\section{Quantitative analysis}

The number of TUNEL-stained epithelial cells in ileal mucosa was counted in fifteen to twenty selected sections from each treatment. The sections were examined under a light microscope. The apoptotic index for each field was calculated as the number of positive TUNEL-stained epithelial cells divided by the total number of epithelial cells counted per field. Means and standard errors were calculated from these counts.

\section{Determination of intestinal mucus secretory IgA}

Mucus secretory IgA (sIgA) was measured using a doubleantibody sandwich ELISA kit (Bethyl). In brief, $1 \mathrm{ml}$ of 0.01 M-PBS was added to an Eppendorf tube containing $0 \cdot 1 \mathrm{~g}$ mucus. The sample was centrifuged at $4{ }^{\circ} \mathrm{C}$ for $10 \mathrm{~min}$ at $3000 \mathrm{~g}$. The supernatant was collected and the content of sIgA was analysed according to the manufacturer's instructions. 


\section{Chemical analysis}

Serum diamine oxidase (DAO) activities were determined by enzymatic spectrophotometry, as described by Li et al. ${ }^{(23)}$. D-Lactate concentrations in serum were measured by enzymatic spectrophotometric assay using a Cobas Fara centrifugal analyser at $30^{\circ} \mathrm{C}$ (Hoffmann-La Roche), according to the method described previously ${ }^{(24)}$. Quantification of endotoxin in serum was determined by the chromogenic Limulus amebocyte lysate test using a chromogenic substrate and individual standard curves for each sample, as described previously ${ }^{(25)}$.

\section{Statistical analyses}

Results are expressed as means with their standard errors. The data of serum parameter, apoptotic index and sIgA content were analysed by the one-way ANOVA procedure of SPSS 16.0 (SPSS, Inc.). For villus height, crypt depth and crypt depth:villus height ratio, the mean value was calculated in each segment. These data were analysed as repeated measures using the mixed procedure of SPSS 16.0 (SPSS, Inc.) according to the following model:

$$
Y_{i j k}=\mu+\alpha_{i}+\beta_{j}+(\alpha \beta)_{i j}+\varepsilon_{i j k},
$$

where $\mu$ is the general effect; $\alpha_{i}$ is the main effect of the $i$ th treatment; $\beta_{j}$ is the main effect of the $j$ th segment; $(\alpha \beta)_{i j}$ is the treatment $\times$ segment interaction; $\varepsilon_{i j k}$ is the residual error. The $\alpha$ level for determination of significance was 0.05. Differences among means were tested by Duncan's multiple range test.

\section{Results}

\section{Intestinal mucosal permeability}

Fig. 1 shows DAO activities, D-lactate levels and endotoxin contents in serum. Compared with pigs that received the control or $100 \mathrm{mg} \mathrm{Zn/kg}$ as $\mathrm{ZnSO}_{4}$ diet, serum DAO activities $(P=0.0001)$ and $\mathrm{D}$-lactate levels $(P=0.0001)$ decreased in pigs fed dietary $100 \mathrm{mg} \mathrm{Zn/kg} \mathrm{as} \mathrm{CS-Zn} \mathrm{or} 3000 \mathrm{mg} \mathrm{Zn/kg} \mathrm{as}$ $\mathrm{ZnO}$. However, compared with pigs that received the control diet, serum endotoxin contents decreased in pigs that received dietary $100 \mathrm{mg} \mathrm{Zn/kg}$ as CS-Zn $(P=0.005)$ or $3000 \mathrm{mg} \mathrm{Zn/kg}$ $(P=0.04)$ as $\mathrm{ZnO}$. No difference was observed for these indices between the pigs fed the diet containing $100 \mathrm{mg} \mathrm{Zn/kg}$ as $\mathrm{CS}-\mathrm{Zn}$ or $3000 \mathrm{mg} \mathrm{Zn} / \mathrm{kg}$ as $\mathrm{ZnO}$. The pigs fed dietary $50 \mathrm{mg}$ $\mathrm{Zn} / \mathrm{kg}$ as $\mathrm{CS}-\mathrm{Zn}(P=0.0001)$ or $100 \mathrm{mg} \mathrm{Zn} / \mathrm{kg}$ as $\mathrm{ZnSO}_{4}$ $(P=0 \cdot 0001)$ showed lower serum D-lactate levels than those fed the control diet. There was no significant difference in serum endotoxin contents between the pigs that received dietary $\mathrm{ZnSO}_{4}$ and those fed the control diet.

\section{Morphological measurements of small-intestinal mucosa}

Morphological measurements of small-intestinal mucosa in pigs are shown in Table 1. The villus height and villus height: crypt depth ratio of duodenal and jejunal mucosa were higher in pigs fed the diet supplemented with $100 \mathrm{mg} \mathrm{Zn/kg}$ as CS-Zn
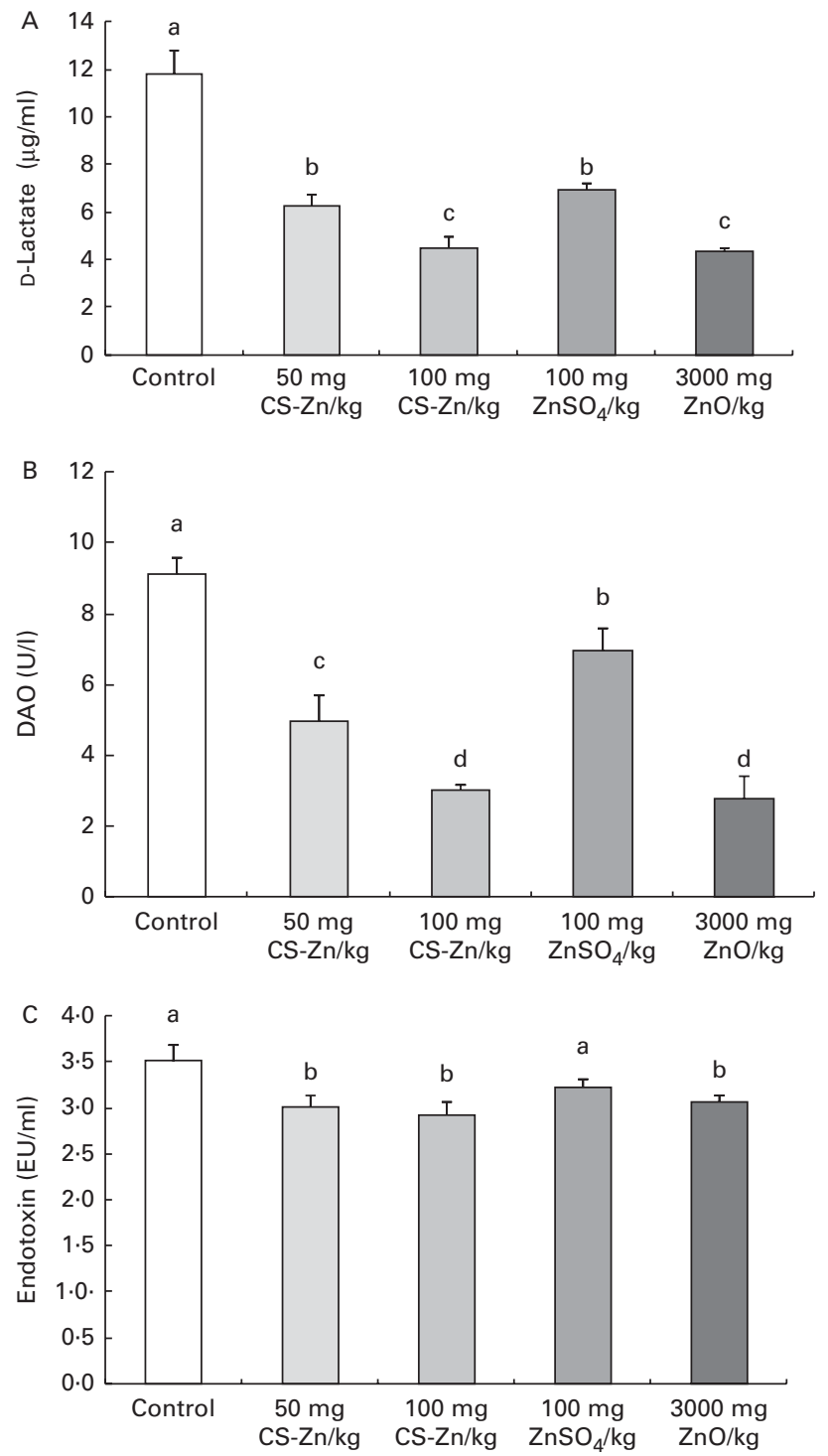

Fig. 1. (A) Serum D-lactate level, (B) diamine oxidase (DAO) activity and (C) endotoxin concentration of weaned pigs fed the control, 50 or $100 \mathrm{mg}$ zinc/kg as chitosan (CS)-Zn, $100 \mathrm{mg}$ zinc/kg as $\mathrm{ZnSO}_{4}$ or $3000 \mathrm{mg}$ zinc/kg as $\mathrm{ZnO}$ diet ( $n 6$ pigs per treatment). ${ }^{\text {a,b,c,d }}$ Mean values with unlike letters were significantly different $(P<0 \cdot 05)$. EU, endotoxin units.

or the high level of $\mathrm{ZnO}$ than in pigs fed the control diet. The crypt depth of the duodenal and jejunal mucosa of these groups was decreased compared with those of the control group. Compared with pigs fed dietary $\mathrm{ZnSO}_{4}$, the villus height and villus height:crypt depth ratio of duodenal mucosa increased in pigs fed the diet supplemented with $100 \mathrm{mg} \mathrm{Zn} / \mathrm{kg}$ as $\mathrm{CS}-\mathrm{Zn}$, while the crypt depth of the duodenum decreased. The villus height:crypt depth ratio of the jejunum was higher in pigs fed dietary $100 \mathrm{mg} \mathrm{Zn} / \mathrm{kg}$ as $\mathrm{CS}-\mathrm{Zn}$ than in those fed dietary $\mathrm{ZnSO}_{4}$, and the crypt depth of the jejunum was lower than that in pigs fed dietary $\mathrm{ZnSO}_{4}$. Compared with pigs fed the control diet, the villus height and villus height:crypt depth ratio of ileal mucosa increased in pigs fed dietary $100 \mathrm{mg} \mathrm{Zn/kg}$ as CS-Zn, while the crypt depth of the duodenum decreased. The crypt 
Table 1. Intestinal villus, crypt depth and villus height:crypt depth ratio of weaned pigs fed the control, 50 or $100 \mathrm{mg}$ zinc/kg as chitosan (CS)-Zn, $100 \mathrm{mg}$ zinc/kg as $\mathrm{ZnSO}_{4}$ or $3000 \mathrm{mg}$ zinc/kg as $\mathrm{ZnO}$ diet

(Mean values with their standard errors, $n 6$ pigs per treatment for each parameter)

\begin{tabular}{|c|c|c|c|c|c|c|c|c|}
\hline \multirow[b]{3}{*}{ Items } & \multicolumn{5}{|c|}{ Zn added (mg/kg feed) } & \multirow[b]{3}{*}{ SEM } & \multirow{2}{*}{\multicolumn{2}{|c|}{$P$}} \\
\hline & \multirow{2}{*}{$\begin{array}{c}\text { Control } \\
0\end{array}$} & \multicolumn{2}{|c|}{ CS-Zn } & \multirow{2}{*}{$\begin{array}{c}\mathrm{ZnSO}_{4} \\
100\end{array}$} & \multirow{2}{*}{$\begin{array}{l}\mathrm{ZnO} \\
3000\end{array}$} & & & \\
\hline & & 50 & 100 & & & & Treatment & Segment \\
\hline \multicolumn{9}{|c|}{ Villus height $(\mu \mathrm{m})$} \\
\hline Duodenum & $455^{c}$ & $475^{\mathrm{b}}$ & $514^{\mathrm{a}}$ & $471^{\mathrm{b}}$ & $516^{a}$ & $5 \cdot 16$ & 0.05 & $<0.001$ \\
\hline Jejunum & $422^{b}$ & $430^{a, b}$ & $441^{\mathrm{a}}$ & $431^{a, b}$ & $440^{\mathrm{a}}$ & $4 \cdot 28$ & & \\
\hline Ileum & 351 & 355 & 364 & 354 & 362 & 3.42 & & \\
\hline \multicolumn{9}{|c|}{ Crypt depth $(\mu \mathrm{m})$} \\
\hline Duodenum & $277^{a}$ & $257^{\mathrm{c}}$ & $231^{c}$ & $261^{\mathrm{b}}$ & $239^{c}$ & 3.37 & 0.02 & 0.04 \\
\hline Jejunum & $274^{a}$ & $244^{\mathrm{b}}$ & $200^{\mathrm{c}}$ & $254^{\mathrm{b}}$ & $196^{\mathrm{c}}$ & 3.06 & & \\
\hline lleum & $234^{\mathrm{a}}$ & $227^{a b}$ & $220^{\mathrm{b}}$ & $226^{a, b}$ & $219^{b}$ & 2.94 & & \\
\hline \multicolumn{9}{|c|}{ Villus height:crypt depth ratio } \\
\hline Duodenum & $1.64^{\mathrm{c}}$ & $1.85^{\mathrm{b}}$ & $2 \cdot 23^{a}$ & $1.81^{\mathrm{b}}$ & $2 \cdot 16^{a}$ & 0.04 & 0.008 & 0.006 \\
\hline Jejunum & $1.54^{\mathrm{c}}$ & $1.76^{\mathrm{b}}$ & $2 \cdot 20^{\mathrm{a}}$ & $1 \cdot 70^{\mathrm{b}}$ & $2 \cdot 24^{a}$ & 0.03 & & \\
\hline lleum & $1.49^{\mathrm{b}}$ & $1.57^{\mathrm{b}}$ & $1.66^{\mathrm{a}}$ & $1.56^{\mathrm{b}}$ & $1.65^{\mathrm{a}}$ & 0.02 & & \\
\hline
\end{tabular}

${ }_{\mathrm{a}, \mathrm{b}, \mathrm{c}}$ Mean values within a column with unlike superscript letters were significantly different $(P<0.05)$.

depth of ileal mucosa was lower in pigs fed the diet supplemented with the high level of $\mathrm{ZnO}$ than in those fed the control diet, and the villus height:crypt depth ratio was higher than that in pigs that received the control diet. As shown in Table 1 , treatment had an effect on villus height $(P=0.05)$, crypt depth $(P=0.02)$ and villus height:crypt depth ratio $(P=0.008)$. The villus height $(p<0.001)$, crypt depth $(P=0.04)$ and villus height:crypt depth ratio $(P=0.006)$ were significantly affected by the segment in the small intestine, with the duodenum having the highest villus height. There was a significant treatment $\times$ segment interaction $(P<0 \cdot 001)$.

\section{TUNEL staining and immunocytochemistry}

Following in situ labelling of ileal mucosal epithelium, microscopic examination revealed stained epithelial cells undergoing apoptosis of ileum in pigs fed the control diet. Apparent TUNEL-stained cells were also found in pigs fed the diet supplemented with $50 \mathrm{mg} \mathrm{Zn} / \mathrm{kg}$ as CS-Zn or $\mathrm{ZnSO}_{4}$. These phenomena were not found in pigs that received the diet containing $100 \mathrm{mg} \mathrm{Zn} / \mathrm{kg}$ as CS-Zn or the high level of $\mathrm{Zn}$ as $\mathrm{ZnO}$. The calculation of the apoptotic index from the quantification of TUNEL-stained cells indicated a significant decrease in ileal epithelial cell apoptosis in pigs fed the diets containing $\mathrm{Zn}$ compared with those fed the control diet (Fig. 2). A statistically significant decrease was found between the pigs fed the diet supplemented with $50 \mathrm{mg} \mathrm{Zn/kg}$ as CS-Zn or $\mathrm{ZnSO}_{4}$ and those that received the diet containing $100 \mathrm{mg} \mathrm{Zn} / \mathrm{kg}$ as CS-Zn or the high level of $\mathrm{Zn}$ as $\mathrm{ZnO}$. There was no significant difference in the apoptotic index of ileal epithelial cells observed between the pigs fed dietary $100 \mathrm{mg}$ $\mathrm{Zn} / \mathrm{kg}$ as CS-Zn and those fed dietary $\mathrm{ZnO}$.

\section{Content of intestinal mucus secretory IgA}

Compared with pigs that received the control or $\mathrm{ZnSO}_{4}$ diet, the level of sIgA in ileal mucus was increased in pigs fed the diet containing $100 \mathrm{mg} \mathrm{Zn/kg}$ as CS-Zn or the high level of $\mathrm{Zn}$ as $\mathrm{ZnO}$ (Fig. 3). The sIgA content in ileal mucus was higher in pigs fed the diet supplemented with $50 \mathrm{mg} \mathrm{Zn/kg}$ as CS-Zn than in those fed the control diet. However, there was no significant difference between the pigs fed the control diet and those fed the diet supplemented with $\mathrm{ZnSO}_{4}$.

\section{Discussion}

In the present study, we found that supplementation with dietary CS-Zn influenced intestinal morphology, ileal mucosal apoptosis and mucosal immune function in weanling pigs. Generally, weaning induces various problems in piglets ${ }^{(26)}$. At the weaning stage, piglets encounter one of the most stressful events including transition of food, environment and maternal and littermate separation. Stress can suppress the immune system and change intestinal physiological function. As a result, a significant reduction in feed intake and

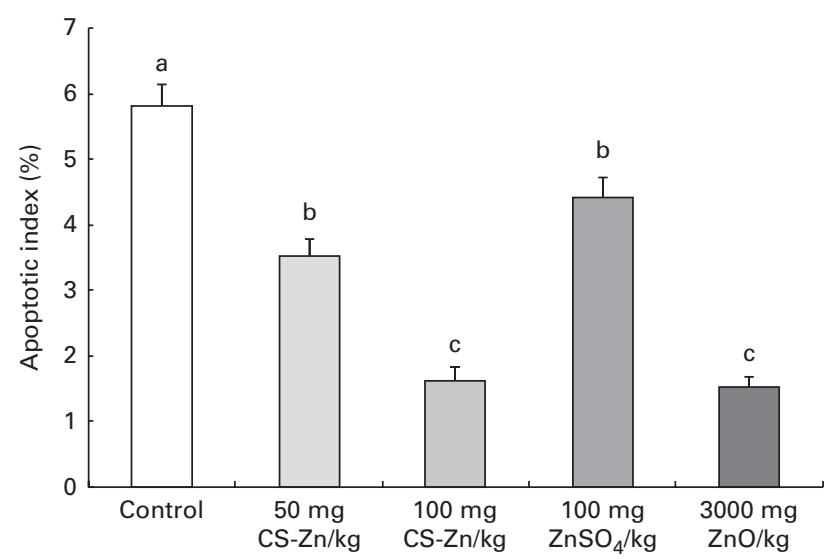

Fig. 2. Apoptotic index calculated for ileal epithelium of weaned pigs fed the control, 50 or $100 \mathrm{mg}$ zinc/kg as chitosan (CS)-Zn, $100 \mathrm{mg}$ zinc/kg as $\mathrm{ZnSO}_{4}$ or $3000 \mathrm{mg}$ zinc/kg as $\mathrm{ZnO}$ diet (n 6 pigs per treatment). ${ }^{\mathrm{a}, \mathrm{b}, \mathrm{c}}$ Mean values with unlike letters were significantly different: a significant decrease of apoptosis $(P<0.05)$ was found in pigs fed the diets supplemented with zinc compared with those fed the control diet. 


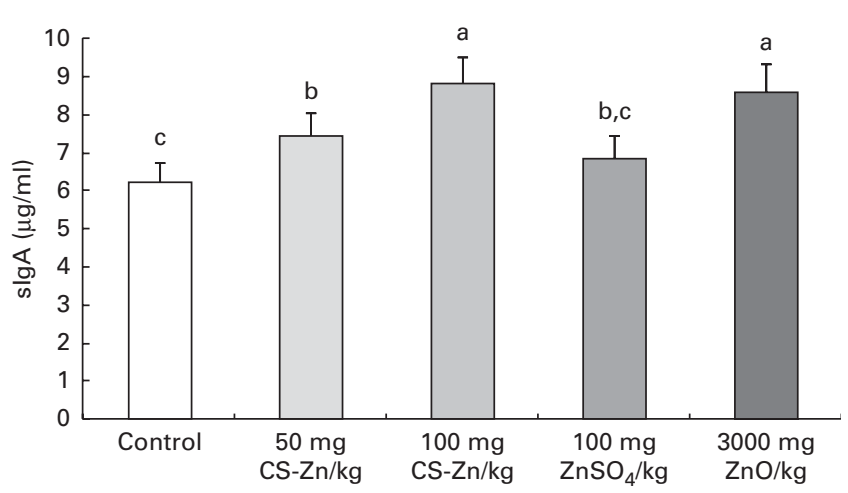

Fig. 3. Secretory $\lg A(\operatorname{sg} A)$ concentration in the ileal mucus of weaned pigs fed the control, 50 or $100 \mathrm{mg}$ zinc/kg as chitosan (CS)-Zn, $100 \mathrm{mg}$ zinc/kg as $\mathrm{ZnSO}_{4}$ or $3000 \mathrm{mg}$ zinc/kg as $\mathrm{ZnO}$ diet (n 6 pigs per treatment for each value). ${ }^{a, b, c}$ Mean values with unlike letters were significantly different $(P<0.05)$.

performance, increased susceptibility to disease and postweaning diarrhoea have usually been observed ${ }^{(27,28)}$. Weaning is also associated with increased intestinal permeability and inflammation, villous atrophy of the small intestine, a decrease in the number of goblet cells and a reduced immunological response, contributing to reduced nutrient absorption and disease resistance ${ }^{(29-31)}$. $\mathrm{Zn}$ is necessary in maintaining intestinal wall integrity and instrumental in maintaining a healthy immune system ${ }^{(32)}$. A study has indicated that $\mathrm{Zn}$ supplementation could contribute significantly to heal the leaky gut ${ }^{(33)}$.

Small-intestinal mucosa makes up the first defence barrier of the intestine, to protect against the entry of micro-organisms and potential pathogens. The small-intestinal mucosal barrier of piglets could be damaged due to the entry of harmful microbes resulting from changes in nutrients and living environment after weanling ${ }^{(34)}$. Serum D-lactate level, DAO activity and endotoxin concentration are useful markers of the permeability of intestinal mucosa, intestinal injury and reperfusion insults ${ }^{(35)}$. In the present study, serum D-lactate level, DAO activity and endotoxin concentration were higher in the control group than in the other groups. The results indicated that small-intestinal integrity may be damaged and the permeability of intestinal mucosa increased. However, these markers were lower in pigs that received the diet supplemented with $\mathrm{ZnO}$ or $100 \mathrm{mg} \mathrm{Zn/kg}$ as CS-Zn but not in pigs fed dietary $\mathrm{ZnSO}_{4}$. The results showed that the high dietary $\mathrm{ZnO}$ level would alleviate the injury of intestinal integrity, which is consistent with a previous study ${ }^{(36)}$. Moreover, dietary $100 \mathrm{mg} \mathrm{Zn/kg}$ as CS-Zn could also protect the integrity of intestinal mucosa and alleviate stress resulting from weaning. This may be the reason that dietary $100 \mathrm{mg} \mathrm{Zn/kg}$ as CS- $\mathrm{Zn}$ could significantly reduce post-weaning diarrhoea ${ }^{(19)}$. Therefore, the body weight of pigs fed dietary $100 \mathrm{mg} \mathrm{Zn/kg}$ as CS-Zn or a high level of $\mathrm{ZnO}$ was similar in the study and was higher than that of pigs fed the control or $\mathrm{ZnSO}_{4}$ diet ${ }^{(19)}$.

The small intestine is the major site for digestion and absorption of nutrients, and intestinal mucosa plays a crucial role during these processes. There exists a positive correlation between intestinal morphology and gut health. The main function of the intestinal villus is nutrient absorption, and the ratio of villus height:crypt depth reflects the status of gut health. Therefore, good intestinal morphology is the physiological basis for nutrient absorption and animal growth. It is well known that changes occur in the gut morphology of piglets after weaning, which include villous atrophy and crypt hyperplasia $^{(37)}$. These changes would lead to the dysfunction of nutrient digestion and absorption in weanling piglets. Some reports ${ }^{(38,39)}$ have shown that a high level of dietary $\mathrm{Zn}$ as $\mathrm{ZnO}$ could increase the villus height and reduce the crypt depth in weanling pigs, and the present results are in conformity with these reports. Moreover, dietary $100 \mathrm{mg} \mathrm{Zn/kg}$ as $\mathrm{CS}-\mathrm{Zn}$ had the same effects as the high level of $\mathrm{Zn}$ as $\mathrm{ZnO}$ and improved small-intestinal morphology. However, dietary $\mathrm{ZnSO}_{4}$ almost had no effect on either villus height or crypt depth. The improvement of intestinal morphology in pigs fed the diet supplemented with $100 \mathrm{mg} \mathrm{Zn} / \mathrm{kg}$ as CS-Zn reflected intestinal integrity and better nutrient absorption, and increased growth performance. Thus, these findings are consistent with the above results of intestinal permeability and integrity.

Villous atrophy means the death or apoptosis of intestinal epithelial cells. Cell apoptosis is a different mode of death from programmed death of necrotic cells. Apoptosis is an autonomic ordered programmed cell death in order to maintain homeostasis, and these processes are controlled by genes. Numerous molecules and approaches are involved in these processes. Zn deficiency in the body could induce cell apoptosis in order to maintain the homeostasis of the internal environment ${ }^{(40)}$. The present data indicated that ileal epithelial cells in pigs fed the diets without $\mathrm{Zn}$ addition were subject to a greater degree of apoptosis. Moreover, pigs fed the diet containing $\mathrm{ZnSO}_{4}$ or $50 \mathrm{mg} \mathrm{Zn} / \mathrm{kg}$ as $\mathrm{CS}-\mathrm{Zn}$ also showed evident apoptosis of epithelial cells. However, the apoptosis was not obvious in pigs that received the diet containing the high level of $\mathrm{Zn}$ as $\mathrm{ZnO}$ or $100 \mathrm{mg} \mathrm{Zn/kg}$ as CS-Zn. These data indicated that a low dietary $Z n$ level would speed epithelial cell apoptosis, leading to the injury of the intestinal mucosal barrier. The present results support the suggestion of Salgueiro et $a l .{ }^{(40)}$. The changes in cell apoptosis in the presence of a high level of dietary $\mathrm{Zn}$ as $\mathrm{ZnO}$ or $100 \mathrm{mg} \mathrm{Zn/kg}$ as CS-Zn might be responsible for the observed effects on small-intestinal morphology and mucosal integrity.

The gastrointestinal tract is not only an organ for digestion, absorption and excretion, but also the largest immunological organ of the body. It acts as the first line of defence against orally administered antigens (e.g. food proteins) and intestinal pathogens (e.g. bacteria, parasites) ${ }^{(41)}$. Weaning piglets are vulnerable to enteric pathogens, and this vulnerability results from factors such as an immature immune system. This can be partly explained by the presence of a low level of sIgA in the intestine $^{(42)}$. SIgA is a protective molecule of the mucosal immune system ${ }^{(43)}$. It has long been recognised as a first line of defence in protecting the intestinal epithelium from enteric pathogenic micro-organisms and toxins ${ }^{(44)}$. The present study found that dietary supplementation of $\mathrm{Zn}$ as CS-Zn or a high level of $\mathrm{Zn}$ as $\mathrm{ZnO}$ increased the small-intestinal sIgA concentration, suggesting that CS-Zn or $\mathrm{ZnO}$ exerts a protective role against pathogen infection. These findings present some 
supporting evidence that $\mathrm{Zn}$ plays an important role in cellmediated immune functions and also functions as an antioxidant and anti-inflammatory agent ${ }^{(45)}$. The functions of $\operatorname{sigA}$ in mucosal immunity and intestinal homoeostasis are not well known, and it is thought that SIgA acts primarily through receptor blockade, steric hindrance, induction of conformational changes and/or immune exclusion, or all of these ${ }^{(45)}$. A healthy immune system can easily block out pathogens, but a weak one may be overrun. The present findings indicated that the increased concentration of intestinal SIgA might be associated with improved intestinal morphology and mucosal integrity. When the immune system is overactive for an extended period of time, a leaky gut can develop.

Conclusively, dietary supplementation of $100 \mathrm{mg} \mathrm{Zn/kg}$ as CS-Zn provided beneficial effects against apoptosis and on the maintenance of intestinal barrier and mucosal immune function, preventing intestinal atrophy and activation absorptive function. Dietary $100 \mathrm{mg} \mathrm{Zn} / \mathrm{kg}$ as CS-Zn was found to be as effective as dietary $3000 \mathrm{mg} \mathrm{Zn} / \mathrm{kg}$ as $\mathrm{ZnO}$. The results demonstrated that CS-Zn might be a kind of new source of $\mathrm{Zn}$ for animals, and further research needs to be carried out.

\section{Acknowledgements}

We thank Bojing Liu and Ya-Li Zhang for their skilful technical assistance.

The present study was financed by the National Science Foundation (31272477). The funder contributed to the conduct of the study, the analysis of the samples and the preparation of the manuscript.

The authors' contributions are as follows: X.-Y. H. and L.-C. Q. designed the research; X.-Y. H., Y.-F. M., M.-Y. L. and Z.-P. W. conducted and analysed the data; X. H. wrote the paper; X.-Y. H. and L.-C. Q. had primary responsibility for the final content. All authors read and approved the final manuscript.

The authors declare that there is no conflict of interest.

\section{References}

1. Mahan DC \& Shields RG Jr (1998) Macro- and micromineral composition of pigs from birth to $145 \mathrm{~kg}$ of body weight. J Anim Sci 76, 506-512.

2. Underwood EJ \& Suttle NF (1999) The Mineral Nutrition of Livestock, 3rd ed. Wallingford: CABI Publishing.

3. Poulsen HD (1995) Zinc oxide for weanling piglets. Acta Agric Scand Sect A: Anim Sci 45, 159-167.

4. Carlson MS, Hill GM \& Link JE (1999) Early- and traditionally weaned nursery pigs benefit from phase-feeding pharmacological concentrations of zinc oxide: effect on metallothionein and mineral concentrations. J Anim Sci 77, 1199-1207.

5. Hill GM, Cromwell GL, Crenshaw TD, et al. (2000) Growth promotion effects and plasma changes from feeding high dietary concentrations of zinc and copper to weanling pigs (regional study). J Anim Sci 78, 1010-1016.

6. Case CL \& Carlson MS (2001) Effect of feeding nursery pigs organic or inorganic sources of zinc on nutrient balance. J Anim Sci 79, Suppl. 1, 51 Abstr.

7. Pluske JR, Hansen CF, Payne HG, et al. (2007) Gut health in the pig. In Manipulating Pig Production XI, pp. 147-158
[JE Paterson and JA Barker, editors]. Werribee, VIC: Australasian Pig Science Association.

8. Poulsen HD \& Larsen T (1995) Zinc excretion and retention in growing pigs fed increasing levels of zinc oxide. Livest Prod Sci 43, 235-242.

9. Case CL \& Carlson MS (2002) Effect of feeding organic and inorganic sources of additional zinc on growth performance and zinc balance in nursery pigs. J Anim Sci 80, 1917-1924.

10. Ward TL, Asche GA, Louis GF, et al. (1996) Zinc-methionine improves growth performance of starter pigs. J Anim Sci $\mathbf{7 4}$, Suppl. 1, 182 Abstr.

11. Wang Y, Tang JW, Ma WQ, et al. (2010) Dietary zinc glycine chelate on growth performance, tissue mineral concentrations, and serum enzyme activity in weanling piglets. Biol Trace Elem Res 133, 325-334.

12. Schell TC \& Kornegay ET (1996) Zinc concentrations in tissues and performance of weanling pigs fed pharmacological levels of zinc from $\mathrm{ZnO}$, Zn-Met, Zn-Lys, or ZnSO 4. J Anim Sci 74, 1584-1593.

13. Crane JK, Naeher TM, Shulgina I, et al. (2007) Effect of zinc in enteropathogenic Escherichia coli infection. Infect Immun 75, 5974-5984.

14. Bhutta ZA, Darmstadt GL, Hasan BS, et al. (2005) Community-based interventions for improving perinatal and neonatal health outcomes in developing countries: a review of the evidence. Pediatrics 115, 519-617.

15. Gielda LM \& DiRita VJ (2012) Zinc competition among the intestinal microbiota. MBio 3, 00112-00171.

16. Zhang B \& Guo Y (2009) Supplemental zinc reduced intestinal permeability by enhancing occluding and zonula occludens protein 1 (ZO-1) expression in weaning piglets. Br J Nutr 102, 687-693.

17. Mcafee BJ, Gould WD, Nadeau JC, et al. (2001) Biosorption of metal ions using chitosan, chitin, and biomass of Rhizopus oryzae. Separ Sci Technol 36, 3207-3222.

18. Wang XH, Du Y \& Liu H (2004) Preparation, characterization and antimicrobial activity of chitosan-Zn complex. Carbohyd Polym 56, 21-26.

19. Xie ZJ, Zhu YM, Han XY, et al. (2010) Effect of chitosan-zinc on growth performance, serum hormone and biochemical indices of weaning piglets. Chin J Anim Nutr 22, 1355-1362.

20. NRC (1998) Nutrient Requirements of Swine, 10th rev. ed. Washington, DC: National Academy Press.

21. Goodlad RA, Levi S, Lee CY, et al. (1991) Morphometry and cell proliferation in endoscopic biopsies: evaluation of a technique. Gastroenterology 101, 1235-1241.

22. Gavrieli Y, Sherman Y \& Ren Sasson SA (1993) Identification of programmed cell death in situ via specific labeling of nuclear fragmentation. J Cell Biol 119, 493-501.

23. Li JY, Lu Y, Hu S, et al. (2002) Preventive effect of glutamine on intestinal barrier dysfunction induced by severe trauma. World J Gastroenterol 8, 168-171.

24. Brandt RB, Siegel SA, Waters MG, et al. (1980) Spectrophotometric assay for D-(-)-lactate in plasma. Anal Biochem 102, $39-46$.

25. Hurley JC, Tosolini FA \& Louis WJ (1991) Quantitative Limulus lysate assay for endotoxin and the effect of plasma. J Clin Pathol 44, 849-854.

26. Van Beers-Schreuers HM, Nabuurs MJ, Kalsbeek-van der Valk HJ, et al. (1998) Weaning and the weaning diet influence the villous height and crypt depth in the small intestine of pigs and alter the concentrations of short-chain acids in the large intestine and blood. J Nutr 128, 947-953.

27. Madec F, Bridoux N, Bounaix S, et al. (2000) Experimental models of porcine post-weaning colibacillosis and their relationship to post-weaning diarrhoea and digestive 
disorders as encountered in the field. Vet Microbiol $\mathbf{7 2}$, 295-310.

28. Boudry G, Guerin S \& Malbert H (2004) Effect of an abrupt switch from a milk-based to a fibre-based diet on gastric emptying rates in pigs: difference between origins of fibre. Br J Nutr 92, 913-920.

29. Smith F, Clark JE, Overman BL, et al. (2010) Early weaning stress impairs development of mucosal barrier function in the porcine intestine. Am J Physiol Gastrointest Liver Physiol 298, G352-G363.

30. Moeser AJ, Borst LB, Overman BL, et al. (2012) Defects in small intestinal epithelial barrier function and morphology associated with peri-weaning failure to thrive syndrome (PFTS) in swine. Res Vet Sci 93, 975-982.

31. Castillo M, Martín-Orúe SM, Nofrarías M, et al. (2007) Changes in caecal microbiota and mucosal morphology of weaned pigs. Vet Microbiol 124, 239-247.

32. Prasad AS, Bao B, Beck FWJ, et al. (2002) Zinc enhances the expression of interleukin-2 and interleukin-2 receptors in HUT-78 cells by way of NF- $\mathrm{BB}$ activation. J Lab Clin Med 140, 272-289.

33. Sturniolo GC, Di Leo V, Ferronato A, et al. (2001) Zinc supplementation tightens leaky gut in Crohn's disease. Inflamm Bowel Dis 7, 94-98.

34. Wu G, Meier SA \& Knabe DA (1996) Dietary glutamine supplementation prevents jejunal atrophy in weaned pigs. J Nutr 126, 2578-2584

35. Murray MJ, Barbose JJ \& Cobb CF (1993) Serum D( - )-lactate levels as a predictor of acute intestinal ischemia in a rat model. J Surg Res 54, 507-509.
36. Hu CH, Qian ZC, Xu HP, et al. (2009) Effects of high Zn on intestinal barrier and expression of tight junction protein in early-weaned piglets. Chin J Anim Vet Sci 40, 1638-1644.

37. Hedemann MS, Højsgaard S \& Jensen BB (2003) Small intestinal morphology and activity of intestinal peptidases in piglets around weaning. J Anim Physiol Anim Nutr 87, $32-41$.

38. Carlson MS, Hoover SL, Hill GM, et al. (1998) Effect of pharmacological zinc on intestinal metallothionein concentration and morphology in the nursery pig. J Anim Sci $\mathbf{7 6}$, Suppl. 1, 57 Abstr.

39. Li BT, van Kessel AG, Caine WR, et al. (2001) Small intestinal morphology and bacterial populations in ileal digesta and feces of newly weaned pigs receiving a high dietary level of zinc oxide. Can J Anim Sci 81, 511-516.

40. Salgueiro MJ, Zubillaga M, Lysionek A, et al. (2000) Zinc as an essential micronutrient: a review. Nutr Res 20,737-755.

41. Scott ME \& Koski KG (2000) Zinc deficiency impairs immune responses against parasitic nematode infections at intestinal and systemic sites. J Nutr 130, 1412S-1420S

42. Ushida K, Kameue C, Tsukahara T, et al. (2008) Decreasing traits of fecal immunoglobulin A in neonatal and weaning piglets. $J$ Vet Med Sci 70, 849-852.

43. Snoeck V, Peters IR \& Cox E (2006) The IgA system: a comparison of structure and function in different species. Vet Res 37, 455-467.

44. Mantis NJ, Rol N \& Corthésy B (2011) Secretory IgA's complex roles in immunity and mucosal homeostasis in the gut. Mucosal Immunol 4, 603-611.

45. Prasad AS (2008) Clinical, immunological, anti-inflammatory and antioxidant roles of zinc. Exp Gerontol 43, 370-377. 